\title{
A myosin inhibitor impairs auxin-induced cell division
}

\author{
Carola Holweg*, Anne Honsel, and Peter Nick \\ Institut für Biologie II, Albert-Ludwigs-Universität Freiburg, Freiburg
}

Received July 30, 2002; accepted August 12, 2003; published online December 19, 2003

(C) Springer-Verlag 2003

\begin{abstract}
Summary. The role of myosins for auxin-induced cell division was probed using the inhibitor 2,3-butanedione monoxime in the tobacco cell line VBI-0, where cell elongation and division are axially aligned under the control of auxin. A morphometric analysis revealed that cell division is blocked in a dose-dependent manner, whereas cell expansion continued. In addition, the polarity of terminal cells was impaired resulting in malformed, pear-shaped cells. Early effects of the inhibitor are aberrant features of the cytoarchitecture including a block of vesicle transport, a diffuse broadening of cross walls, and the disorganization of the actin cytoskeleton. The findings are discussed with respect to a possible role of myosins as link between vesicle flow and signal control of cell division.
\end{abstract}

Keywords: Actin; 2,3-Butanedione monoxime; Cell division; Cell plate; Myosin; Tobacco.

Abbreviations: BDM 2,3-butanedione monoxime; VBI-0 tobacco (Nicotiana tabacum L.) cv. Virginia Bright Italia.

\section{Introduction}

In addition to internal signals, plant growth is controlled by external stimuli that determine cell division and cell expansion. The growth responses to these signals have been shown to be intimately linked to the cytoskeleton. Microtubules (for a review, see Nick 1998) as well as actin microfilaments (for a review, see Staiger 2000) have been shown to link signal transduction to plant morphogenesis.

The role of the actin cytoskeleton in cell growth has been intensively studied for tip-growing cells such as pollen tubes or root hairs (for a review, see Geitmann and Emons 2000). Not the same attention has been paid to the function of actin for the expansion of the vast majority of

\footnotetext{
* Correspondence and reprints: Institut für Biologie II, AlbertLudwigs-Universität Freiburg, Schänzlestrasse 1, 79104 Freiburg, Federal Republic of Germany.
}

cells that are integrated into a tissue such that growth is not localized to narrow regions of the cell. Nevertheless, actin seems to be an essential component of tissue expansion as well because it can be inhibited by blockers of actin assembly such as cytochalasin (Thimann et al. 1992) or latrunculin (Baluška et al. 2001). Moreover, the response of organ growth to signals such as phytochrome or auxin has been found to be accompanied by corresponding responses of actin microfilaments (Waller and Nick 1998, Waller et al. 2002). Thus, the control of cell growth by actin seems to be a general feature of plant cells that is not confined to tip growth.

In contrast to cell expansion, the role of actin during cell division is far from being understood. In sharp contrast to the pronounced ephemerism of microtubular arrays during mitosis, transvacuolar and cortical actin cables persist forming a characteristic structure, termed phragmosome (for a review, see Lloyd 1991). Due to its high diffraction, the phragmosome is prominent even in bright-field microscopy and has been described as Maltese cross at a time when plant actin was not even believed to exist. The phragmosome was proposed to tether the nucleus in the correct division plane. In addition, actin might provide a kind of "spatial memory" that aligns the microtubular cytokinetic apparatus with the division plane. Positioning of the nucleus by actin cables (Katsuta and Shibaoka 1988) seems to be decisive for the re-formation of the preprophase band that marks the location of the prospective cell plate (Murata and Wada 1991). This implicates that the spatial control of cell division is based upon actin-dependent intracellular movements. We therefore ventured to ask for the impact of plant myosins on cell division.

In contrast to plants, animal and fungal myosins have been investigated in great detail (for a review, see Sellers 
2000). Meanwhile, myosins are grouped into 18 classes according to the conserved head domain (Yamashita et al. 2000). This conserved head domain harbors the binding to actin and the ATPase functions and thus the essential components for the power stroke that has been studied at length for the muscle myosin of class II (for a review, see Sellers 2000). Interestingly, the progressively growing number of sequences for plant myosins fall into only three classes that are separate from the other myosins (for reviews, see Shimmen et al. 2000, Reddy and Day 2001). Concerning their functions, early studies showed correlations between actomyosin and cytoplasmic streaming (Nagai 1979) and gave first indications for the interaction between the power stroke of myosin and organelle translocation (Menzel and Elsner-Menzel 1989). Although plant myosins have been repeatedly localized with cross-reacting antisera raised against muscle myosin (for a review, see Shimmen et al. 2000) or one recombinant plant myosin (Reichelt et al. 1999), little is known about their cellular function. In most cases, the specific functions of plant myosins have still to be derived from sequence homologies with nonplant myosins of known function (Mooseker and Cheney 1996). For instance, from the sequence similarity between the tail domains of class XI with class V myosins the class XI plant myosins have been proposed to be involved in organelle transport (Sellers 2000).

To identify cellular effects of myosin activity as a framework for subsequent studies on specific myosins, one could use inhibitors that block a target essential for all myosins. Blockers of SH- groups (which are abundant in the myosin head domain) such as N-ethylmalemide or kinase inhibitors such as ML9 can be used to inhibit myosins, but their mode of action is expected to affect unrelated proteins as well (Karlsson and Lindberg 1985, Saitoh 1987). A more specific target would be the ATPase function that is required for the power stroke and can be blocked by 2,3-butanedione monoxime (BDM). BDM stabilizes the ADP. $\mathrm{P}_{\mathrm{i}}$-bound state of myosins and thus halts the release of $\mathrm{P}_{\mathrm{i}}$ which normally would produce the power stroke (McKillop et al. 1994). Although BDM has to be administered at high doses when tested in in vitro motility assays, $20 \mathrm{mM} \mathrm{BDM}$ still leaves $25 \%$ of the activity (Herrmann et al. 1992, Higuchi and Takemori 1989). However, in contrast to the findings of Cramer and Mitchison (1995), who showed that the ATPase activity of nonmuscle myosins is inhibited by BDM, the recently published results of Ostap (2003) challenge the use of $\mathrm{BDM}$ as a "general" myosin inhibitor.

In addition to its direct effect on the ATPase function of myosins, BDM also has been suggested to affect kinase- related proteins. This would therefore interfere indirectly with myosins but also with other proteins via different signal pathways (Grabski et al. 1998). Moreover, a possible impact of BDM on calcium channels has been discussed for animal cells (Sellin and McArdle 1994). Nevertheless, BDM has been successfully used in plants to test the participation of myosins in a range of cellular functions such as cytoplasmic streaming in Chara corallina (Nagai 1979), plasmodesmatal closure, maturation of cell plates (Radford and White 1998), anisotropic cell elongation (Baskin and Bivens 1995), or the movement of Golgi stacks (Nebenführ et al. 1999). In vitro studies with myosin fractions isolated from lily pollen tubes show reduced motility after treatment with BDM (Tominaga et al. 2000) and a plant myosin VIII failed to preserve its characteristic distribution in the presence of BDM (Samaj et al. 2000). Taken together, BDM seems to be a useful drug for myosin-related observations. However, its mode of action on individual plant myosins and possibly additional cellular targets remains to be elucidated.

To test a possible role of myosins in cell division, we analyzed the effect of BDM in the tobacco cell line VBI0 . This cell line is characterized by axial cell division and cell expansion that can be triggered by auxin and produce pluricellular, polar cell files (Petrášek et al. 1998). Cell division can therefore be controlled by a specific signal, the cells are large and well suited for cell-biological studies, and the axiality of division and expansion is well defined. Therefore, this system is ideal for cell-biological studies on the spatial control of cytokinesis. Using this system and BDM as inhibitor of myosin action, we addressed the question which events of cell division depend on myosins. We found that BDM blocked cell division at conditions that still allowed cell expansion to proceed and identified vesicle traffic, cell plate formation, and actin organization as myosin-dependent events. This can be used in future studies to allocate these cellular events to the respective subclasses of plant myosins.

\section{Material and methods}

Cell culture and treatment with myosin blockers

The tobacco cell line VBI-0 (Nicotiana tabacum L. cv. Virginia Bright Italia) derived in 1967 from stem pith tissue (Opatrný and Opatrná 1976) was maintained from a stock callus culture on slightly modified Heller (1953) medium, supplemented with 1-naphthylacetic acid $(5 \mu \mathrm{M})$ and 2,4-dichlorophenoxyacetic acid $(5 \mu \mathrm{M})$. Every three weeks cells were subcultivated in a volume of $30 \mathrm{ml}$ of fresh medium in Erlenmeyer flasks to an inoculation density of $1.2 \times 10^{5}$ cells per $\mathrm{ml}$. The cell suspensions were maintained in darkness at $25^{\circ} \mathrm{C}$ on a horizontal shaker at $150 \mathrm{rpm}$. For morphometric studies 0, 1, 5, or $10 \mathrm{mM}$ BDM (Sigma-Aldrich, Deisenhofen, Federal Republic of Germany) was added at the time of 
subcultivation. To test whether the inhibition of cell division by BDM was reversible, the cells were first cultivated for two days in the presence of BDM, and after washing the cells once under sterile conditions, they were transferred to a medium that was free of BDM.

\section{Morphometry}

Aliquots of cells were taken at various times after inoculation. The cell's viability was determined with the vital dye Trypan Blue (Sigma-Aldrich) and bright-field images were obtained by a digital imaging system (Axiovision; Zeiss, Oberkochen, Federal Republic of Germany). The images were transformed into the TIF format and subjected to quantitative image analysis (Image J; National Institute of Mental Health, Bethesda, Md., U.S.A.) using the perimeter and analyze functions. Cell lengths were then calculated on the basis of the pixels-per-micrometer ratio given by the respective objective. The data were statistically tested at the 95\% significance level. The experimental series were run three to five times in independent culture cycles with 100 to 300 individual cell files per data point.

\section{Visualization of the endomembrane system and actin cytoskeleton}

For cell-biological studies, cells were isolated during various stages of the culture cycle and treated with higher $(30-50 \mathrm{mM}$ BDM) concentrations for $2 \mathrm{~h}$ and directly used for the visualization of actin or endomembranes or for differential interference contrast microscopy (Axioskop; Zeiss).

Cells were stained for $5 \mathrm{~min}$ with $10 \mu \mathrm{g}$ of rhodamine-G6-chloride (Molecular Probes, Leiden, Netherlands) per $\mathrm{ml}$ in Heller medium, washed for $10 \mathrm{~min}$ in dye-free medium, and directly observed by epifluorescence microscopy (Axioskop; Zeiss) with a rhodamine filter set (set 15; Zeiss) or confocal laser scanning microscopy with an argonkrypton laser (TCS 4D; Leica, Bensheim, Federal Republic of Germany) with excitation at $568 \mathrm{~nm}$, a beam splitter at $580 \mathrm{~nm}$, and a barrier filter at $590 \mathrm{~nm}$ and a line averaging algorithm with 16 individual scans.

Actin microfilaments were visualized by a protocol adapted from Sonobe and Shibaoka (1989). The cells were pretreated for $30 \mathrm{~min}$ in a cross-linker solution of $300 \mu \mathrm{M} \mathrm{m}$-maleimidobenzoyl N-hydroxysuccinimide ester (MBS) (Sigma-Aldrich) in phosphate-buffered saline (PBS) $(140 \mathrm{mM}$ $\mathrm{NaCl}, 2.7 \mathrm{mM} \mathrm{KCl}, 10 \mathrm{mM} \mathrm{K} \mathrm{HPO}_{4}, 1.8 \mathrm{mM} \mathrm{KH}_{2} \mathrm{PO}_{4}, \mathrm{pH}$ 7.4) containing $0.05 \%(\mathrm{v} / \mathrm{v})$ Triton $\mathrm{X}-100$. After removing the MBS solution and washing with PBS, cells were fixed in $1.8 \%(\mathrm{w} / \mathrm{v})$ paraformaldehyde in PBS for $60 \mathrm{~min}$. After a further washing step, actin was stained with $33 \mathrm{nM}$ tetramethylrhodamine isothiocyanate-conjugated phalloidin (Molecular Probes) in PBS, and the cells were directly observed by confocal laser scanning microscopy using the same setup as for rhodamineG6-chloride staining.

\section{Results}

\section{BDM blocks cell division in dose-dependent manner}

To assess the effect of the myosin inhibitor BDM on cell growth and division, we monitored the length of individual cells and the number of cells in pluricellular files through a culture cycle triggered at day zero by the addition of auxin. Frequency distributions over the number of cells constituting a file (Fig. 1A) show that the frequency of unicellular files is maximal at the time of induction with auxin but decreases progressively to a minimum at day 8. During the second phase of the culture cycle, the frequency of unicellular files gradually recovers to the initial situation. At day 8, the majority of files consists of four or more cells. These files disintegrate subsequently, causing the recovery in the frequency of singular cells. In the presence of $5 \mathrm{mM} \mathrm{BDM}$, this typical sequence of cell division of VBI-0 cells is changed characteristically (Fig. 1B): At day 4, nearly $70 \%$ of the files are still singular, whereas untreated cells have divided repeatedly to form files with 2-4 cells. In addition, the maximal number of cells per file is conspicuously reduced from 10 in the control to 6 or lower in the presence of BDM. Interestingly, the disintegration of cell files is delayed to some extent during the second phase of the culture cycle. Whereas in the absence of BDM, singular cells prevail at the end of the culture cycle at day 20 , bicellular or even pluricellular files are still relatively frequent in the presence of BDM.

These effects of BDM on cell division are dose dependent. When the frequency of unicellular files is monitored over time (Fig. 1C), the decrease between days zero and 8 is only slightly affected by $1 \mathrm{mM}$ BDM, but drastically suppressed by $5 \mathrm{mM}$ BDM. Interestingly, the recovery of unicellular files (due to the disintegration of bi- and pluricellular files at the end of the culture cycle) is already dramatically blocked by $1 \mathrm{mM}$ BDM. The frequency of bicellular files (Fig. 1D), which are most common at day 4 in the control, remains mostly unchanged during the early phase of the culture when $1 \mathrm{mM}$ BDM is administered, whereas $5 \mathrm{mM}$ causes a clear delay by about 2 days. The most striking effect is seen for the occurrence of pluricellular files (Fig. 1E): BDM causes a delay in the peak and reduces the amplitude of the division response. Here, $1 \mathrm{mM}$ BDM produces already a significant inhibition that is even further amplified for $5 \mathrm{mM}$ BDM. These data indicate that the first division step producing bicellular files is less sensitive as compared with the subsequent divisions that will produce pluricellular files.

The number of divisions in BDM-treated cultures is significantly lower as compared with the control. A plot of the average number of cells per file over time (Fig. 2A) reveals that already for $1 \mathrm{mM}$ BDM the average cell number per file is decreased to about $80 \%$ of the control value. A dose-response relation of this effect for the peak of division at day 8 (Fig. 2B) shows a threshold below $1 \mathrm{mM}$ and saturation for $5-10 \mathrm{mM}$ of BDM. For these concentrations, the viability of the dividing cells did not show any differences as compared with control cells (data not shown), demonstrating that the inhibition of cell division by BDM is not caused by unspecific intoxication. 

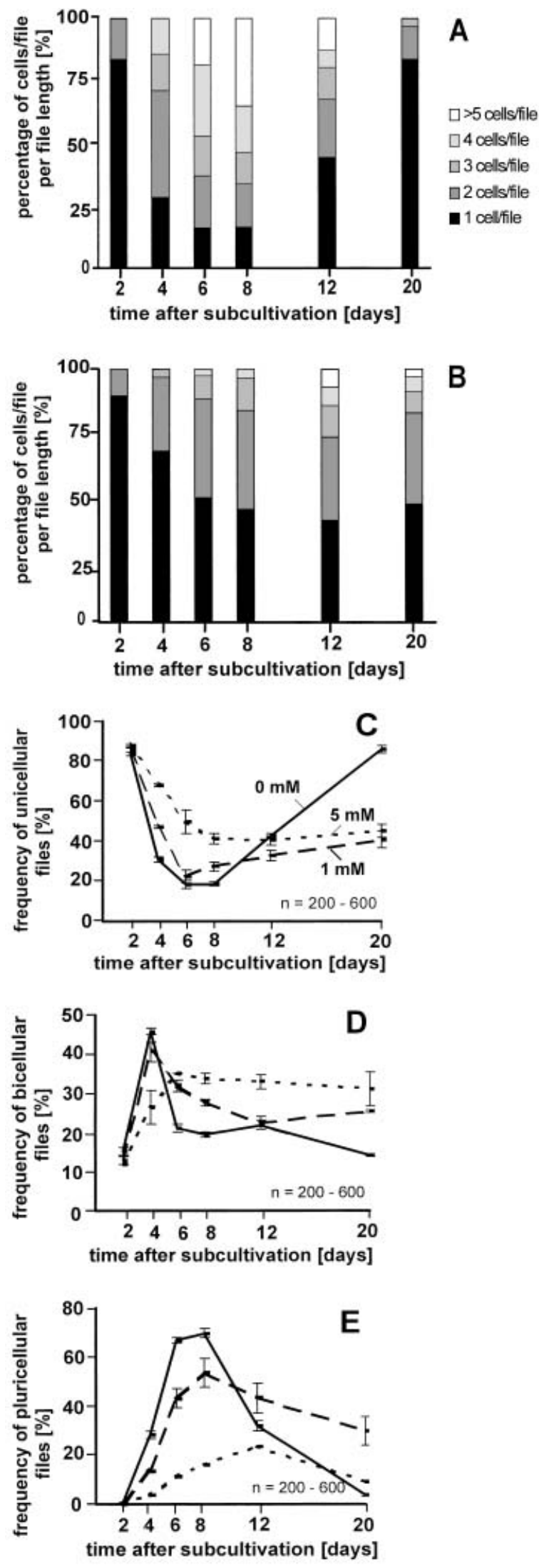

Additional control experiments (Fig. 2C) tested the reversibility of the inhibition by BDM. When the inhibitor was washed out after 2 days, the cell number per file was fully restored and within 4 days reached the value observed in untreated controls.

\section{BDM does not inhibit cell elongation}

The cell length was monitored through the culture cycle for different concentrations of BDM (Fig. 3A). In untreated controls, the cell length dropped continuously to about $30 \%$ of the initial value at day 8 , when the number of individual cells per file was maximal. Subsequently, the length gradually recovered to the initial value. This drop during the first part of the culture cycle was progressively inhibited by increasing concentrations of BDM. Interestingly, it was converted into an apparent stimulation of cell elongation for the highest concentration used $(10 \mathrm{mM})$. The increase of cell length is also obvious in Fig. 3B, where the average cell length was measured in bicellular files that had undergone one division at day 4 of the culture cycle. The average cell length was found to increase progressively with increasing doses of BDM. Thus, in contrast to its inhibition of cell division, BDM does not impair cell elongation (Fig. 3C). The apparent increase of cell length does not necessarily mean that cell elongation is stimulated, but it might be caused by the delayed cell division in the BDM-treated cells that would therefore elongate during a longer interval before the cell length is again reduced by the subsequent division. To take this point into account, we calculated how long the cells would be at day 6 under the assumption that there is no cell elongation at all, but only the progressive reduction of cell length in consequence of the ongoing divisions (that can be deduced from Fig. 2A). We used this value as reference for the cell length that was actually observed. The length increment of the observed value over the calculated reference value (expressed in percent of the reference value) is therefore a measure for the degree of active elongation. When this length increment is plotted over the concentration of BDM (Fig.3D), there is no difference between control and BDM-treated samples, even for the highest concentration used. In other words, the increase in cell length in response

Fig. 1A-E. BDM inhibits the formation of pluricellular files in response to auxin. Frequency distributions of cell number per file over time after the addition of auxin in the absence (A) or presence of $5 \mathrm{mM}$ BDM (B). Frequency of unicellular (C), bicellular (D) and pluricellular (at least 3 cells) cell files (E) during the response to auxin in the absence (solid line) or presence of $1 \mathrm{mM}$ (dashed line) and of $5 \mathrm{mM}$ BDM (dotted line) 


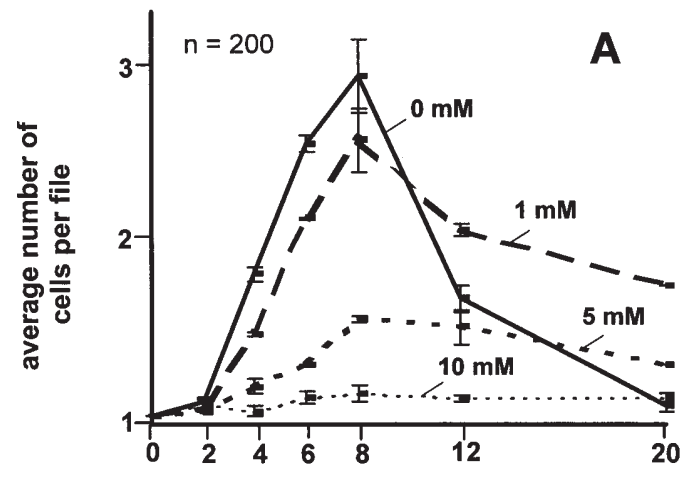

time after subcultivation [days]
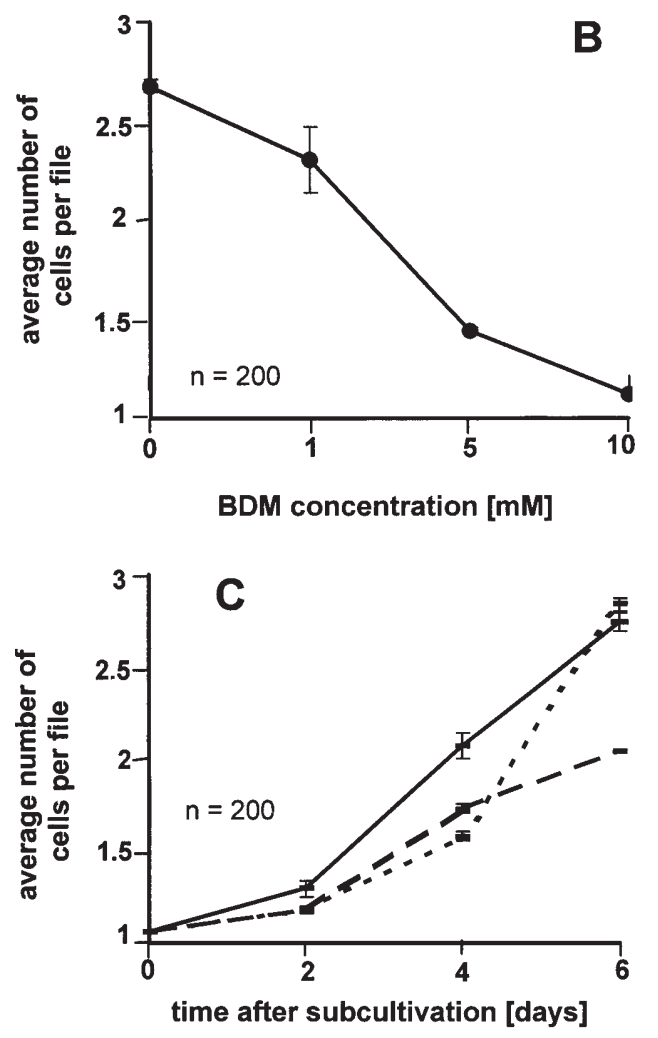

Fig. 2A-C. Effect of BDM on cell division. A Average number of cells per file in the absence (solid line) or presence of $1 \mathrm{mM}$ (dashed line), $5 \mathrm{mM}$ (dotted line), and $10 \mathrm{mM}$ BDM (thin dashed line) plotted against the time after subcultivation (addition of auxin). B The maximal inhibition of BDM was observed at day 8 and was used for the dose-response curve shown. C Reversibility of the BDM effect, when BDM is washed out at day 2 (dotted curve). The time course of untreated controls (solid line) and a parallel experiment in which BDM was not washed out (dashed curve) are shown for comparison

to BDM is not caused by a stimulation of elongation per se but is caused by reduced cell division at a simultaneously more or less unchanged rate of elongation - if a cake is cut into less pieces, the pieces will become bigger in size. We therefore arrive at the conclusion that BDM does not affect cell elongation in VBI-0 cells.
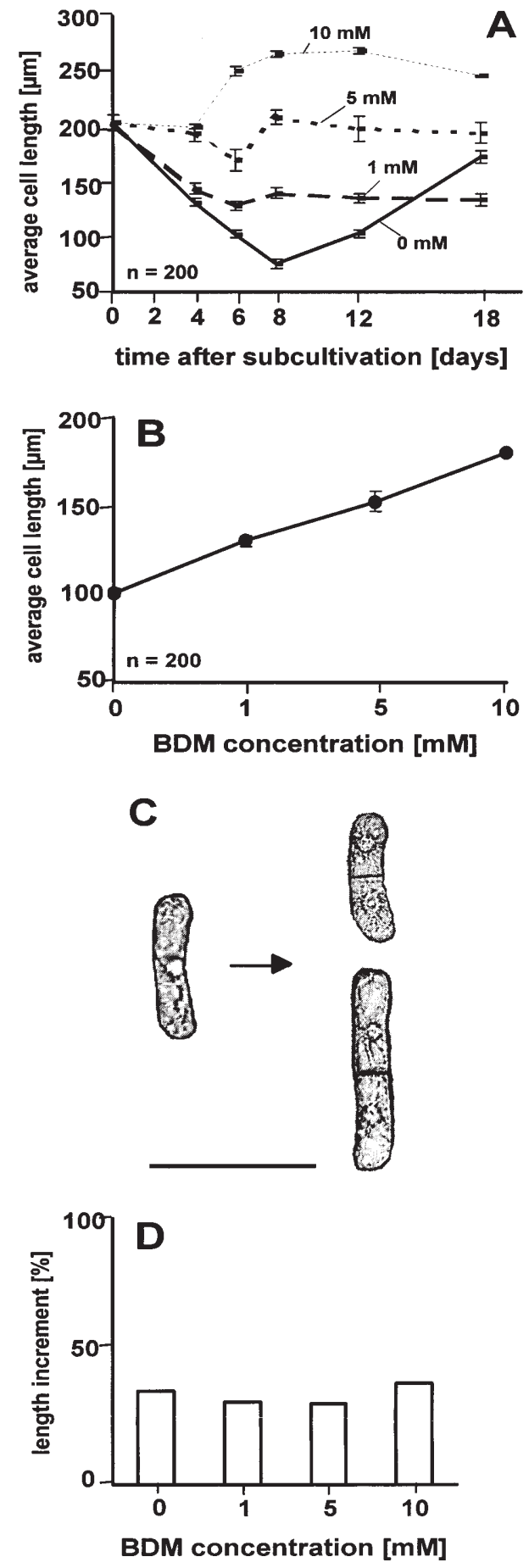

Fig. 3A-D. Effect of BDM on cell elongation during the logarithmic phase of the culture. A Average cell length over time after subcultivation (addition of auxin). B Dose response of cell length after the first cell division (in bicellular files) to BDM. C Representative bicellular files in controls (upper row) and cells treated with $5 \mathrm{mM}$ BDM (lower row). Bar: $100 \mu \mathrm{m}$. D Increment of observed cell length 6 days after subcultivation over the expected length, when cells would not elongate but only divide. The value is given as percentage of the expected value 
A
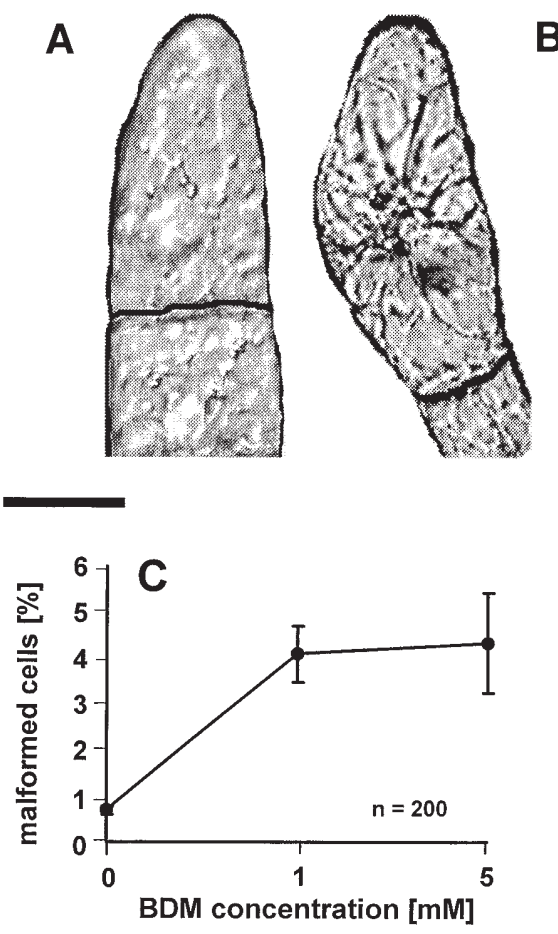

Fig. 4A-C. Loss of growth polarity in terminal cells in response to BDM. A Control cell with pronounced polarity. B Cell treated with $1 \mathrm{mM}$ BDM producing a pear-shaped swelling. Bar: $50 \mu \mathrm{m}$. C Dose response for the frequencies of malformations

\section{BDM impairs polar growth}

VBI-0 cells normally maintain a strict axiality of cell growth parallel to the long axis of the file and a clear polarity of the terminal cell at the tip of the file (Fig. 4A). BDM causes malformations such as pear-shaped swellings that seem to be caused by a lateral shift of the growth center (Fig. 4B). The frequency of these malformations is dramatically increased already for $1 \mathrm{mM}$ BDM, reaching a saturation level that cannot be exceeded by increasing the concentration (Fig. 4C).

\section{BDM interferes with cytoplasmic organization and vesicle traffic}

The effect of BDM on the cytoplasmic organization was monitored by differential interference contrast microscopy (Fig. 5A-C). The prominent cytoplasmic strands emanating from the nucleus of control cells (Fig. 5A) are replaced within $3 \mathrm{~h}$ by vesicular structures that accumulate around the nucleus (Fig. 5B) or are aligned as strings of beads along delicate, filamentous structures (Fig. 5C2, C3). Additionally, the cross walls appear to broaden in a diffuse manner and are accompanied by fine lamellate structures (Fig. 5C1). Visualization of the endomembrane system with rhodamine-G6-chloride shows that the clear radial structure emanating as broad strands from the nuclear envelope in the control (Fig. 5D) is dissolved into vesiculate clusters conglomerating around the nucleus and, in a seemingly chaotic distribution, throughout the cytoplasm (Fig. 5E).

\section{BDM disorganizes the actin cytoskeleton}

In control cells, more or less longitudinal subcortical bundles of actin coexist with fine, delicate and mostly transverse cortical microfilaments (Fig. 6A). Treatment with BDM mainly affects the longitudinal subcortical bundles of actin (Fig. 6B2), whereas the transverse cortical microfilaments are surprisingly persistent (Fig.6B3). Under prolonged treatment, this alignment of actin with the axis of the cell is completely lost (Fig. 6C), and the actin cytoskeleton even dissolves, whereby more or less disorganized remnants persist usually around the perinuclear region (Fig. 6D) or along the cross walls (Fig. 6E).

\section{Discussion}

\section{Cell division is a sensitive target for BDM}

The myosin inhibitor BDM was used to identify cellular events that depend on myosins. Interestingly, the most prominent effect was observed upon division, whereas cell elongation continued. The effects at higher BDM concentrations were alterations of actin organization, inhibition of vesicle traffic, and impaired polarity in the terminal cells. The inhibition of cell division occurred in a dose-dependent manner, was fully reversible (Fig. 2C), and reached its saturation at 5-10 $\mathrm{mM}$, indicating a comparatively high sensitivity. During in vitro motility assays with myosins, between $20 \mathrm{mM}$ (muscle myosin; Herrmann et al. 1992, Higuchi and Takemori 1989) and $60 \mathrm{mM}$ (lily pollen myosin; Tominaga et al. 2000) had to be used to suppress myosin activity to a residual level of $25 \%$. Thus, along with the swelling of Arabidopsis thaliana roots that can be induced by $10 \mathrm{mM}$ BDM (Baskin and Bivens 1995), the inhibition of cell division in VBI-0 cells ranges among the most sensitive plant responses to BDM. For instance, $60 \mathrm{mM} \mathrm{BDM}$ had to be administered to produce rearrangements of transvacuolar strands in root hairs of Limnobium stoloniferum (Yokota et al. 2000). The reason for these different sensitivities to BDM to vary considerably by a factor of 5-10 in plants is not understood, but it could be related either to the extent of actomyosin dynamics or to the impact of different myosin classes.

A comparative study on ATPase activities that has been recently published (Ostap 2003) comes to the conclusion that 

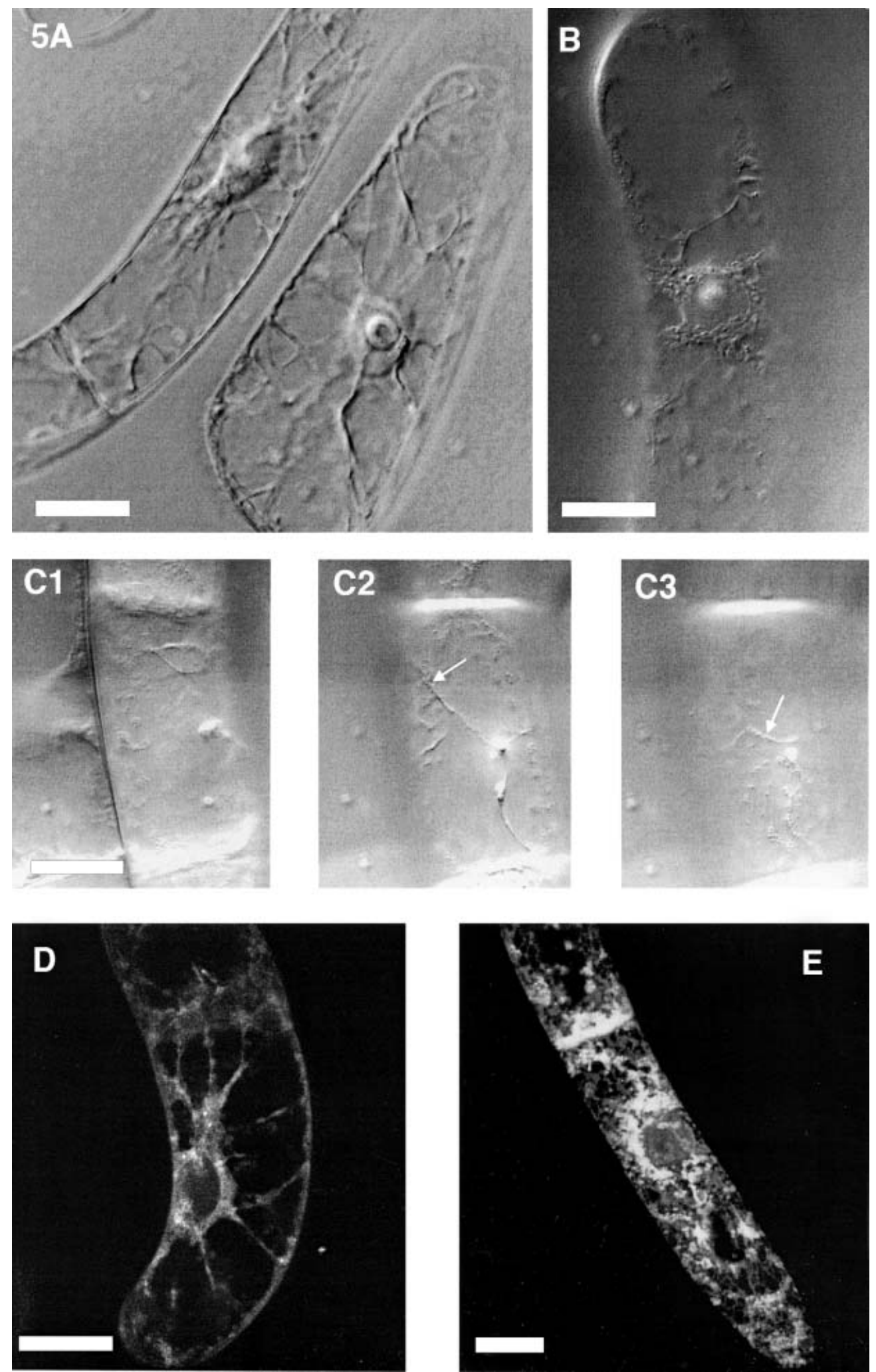

Fig. 5A-E. Inhibition of vesicle trafficking by BDM. A Control cells with cytoplasmic strands radiating from the nucleus to the cell periphery. B and C Cells treated with 30-50 mM BDM for $2 \mathrm{~h}$ showing clusters of vesicles around the nucleus $(\mathbf{B})$ and strings of beads (arrow in $\mathbf{C 2}$ and $\mathbf{C 3}$ ), note the accumulation of vesicles near thickened cell walls $(\mathbf{C 1}$ and $\mathbf{C 2})$. D and $\mathbf{E}$ Visualization of the endomembrane system by rhodamine-G6-chloride in control cells (D) versus BDM-treated cells $(\mathbf{E})$. Note the clusters of vesicles around the nucleus as well as adjacent to the cross walls. Bars: $20 \mu \mathrm{m}$ 

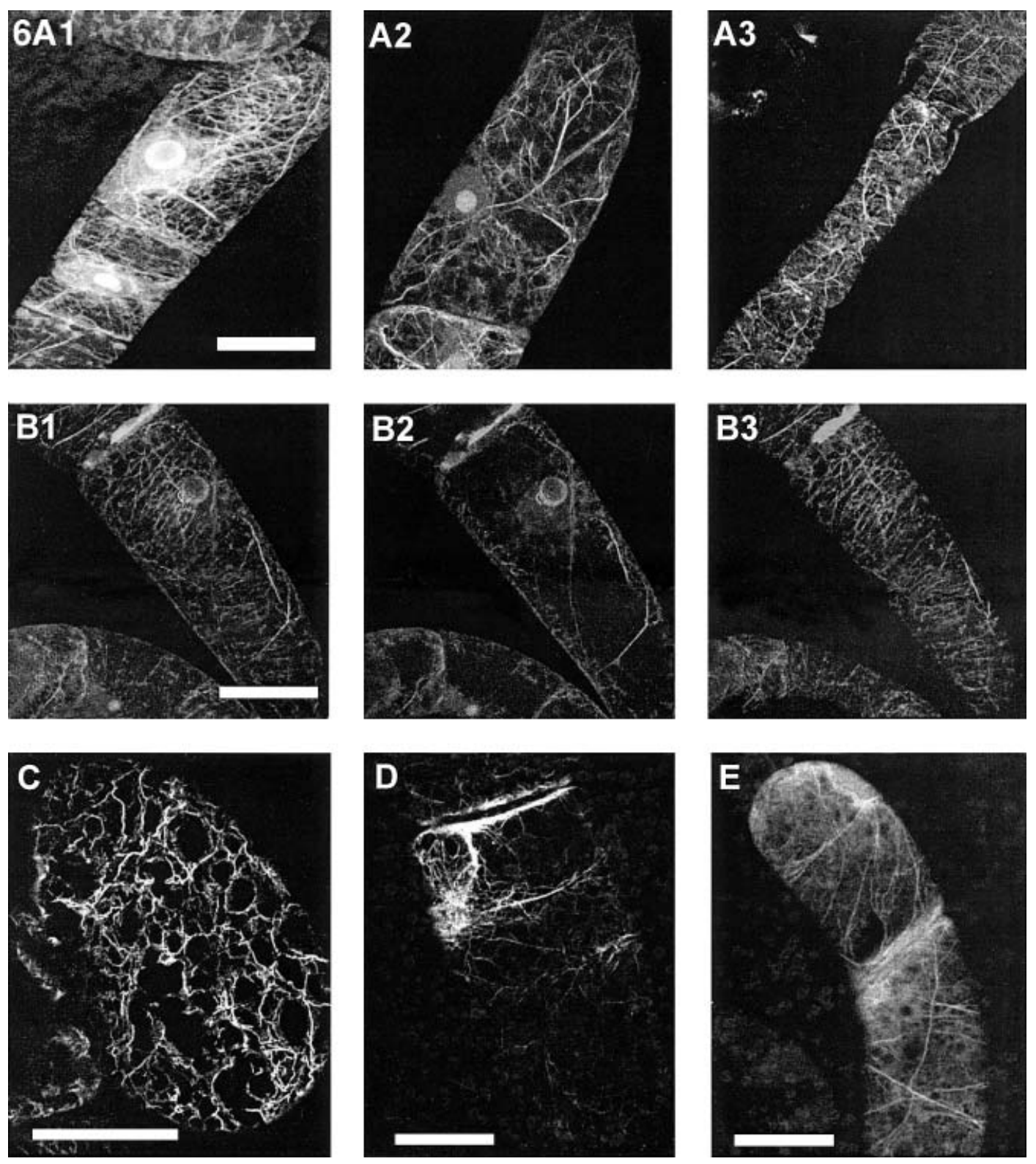

Fig. 6A-E. Alterations of actin organization in response to BDM. A Projections of confocal stacks collected from control cells with axially oriented subcortical actin bundles and transversely oriented cortical actin microfilaments. B1-3 Projection (B1) and two confocal sections of a cell treated for $2 \mathrm{~h}$ with $30 \mathrm{mM}$ BDM illustrating the partial loss of subcortical actin bundles, whereas cortical microfilaments persist. C Complete loss of actin alignment after treatment with $50 \mathrm{mM} \mathrm{BDM}$ for $2 \mathrm{~h}$. D Accumulation of actin strands around the nucleus. $\mathbf{E}$ Accumulation of diffuse actin at the cell pole and adjacent to the cross walls (treatment of the cells shown in panels D and $\mathrm{E}$ was the same as for those shown in panel C). Bars: $20 \mu \mathrm{m}$

BDM inhibits the ATPase activity of myosin class II from skeletal muscle, whereas others like chicken myosin $\mathrm{V}$ and porcine myosin VI remain essentially unaffected in vitro. These findings challenge the use of BDM as a "general" myosin inhibitor. Furthermore, during an extensive study on myosin-dependent processes such as cytoplasmic streaming in Chara corallina, chloroplast movement in Elodea sp., or the formation of Golgi-derived aggregations in response to the fungal toxin Brefeldin A in root cells (McCurdy 1999), BDM at concentrations up to $20 \mathrm{mM}$ was observed to be not effective. This study proposed that BDM effects reported for plant cells might result from inhibitory effects on calcium channels caused via its chemical phosphatase activity (McCurdy 1999, Sellin and McArdle 1994). The inhibition of putative voltage-operated L-type calcium channels in the tonoplast as well as in plasma membranes (Johannes et al. 1991) would affect the general homeostasis of calcium and thus, indirectly, myosin activity in addition to numerous other effects (Staiger 2000, Yokota et al. 1999). However, the block of cell division by BDM on the back- 
ground of unaffected elongation would call for a more specific mode of action rather than a general change of calcium levels.

In fact, numerous studies have shown effects of BDM on myosins. For instance, by immunofluorescence with antibodies directed to plant myosin VIII, these myosins were shown to be dislocalized after treatment with BDM treatment (Samaj et al. 2000). Furthermore, it was shown by in vitro sliding tests that myosin isolated from lily pollen tubes is suppressed by BDM in vitro (Tominaga et al. 2000). These and several other studies allow to assume a significant inhibitory effect of the drug at least on some unconventional myosins. Distinct myosins encoded by large gene families in plants could have differential sensitivity to BDM. As discussed by Ostap (2003), the efficiency of BDM on the ATPase activity of chicken myo$\sin \mathrm{V}$ might depend on whether recombinant or native motor domains were used. In contrast to the recombinant chicken myosin V (Ostap 2003), native myosin V was previously reported to be BDM sensitive (Cramer and Mitchison 1995). Higher-plant myosin XI, which is the closest plant relative of myosin $\mathrm{V}$ and encoded by 13 different genes in Arabidopsis thaliana (Reddy and Day 2001), was reported to be clearly inhibited by BDM (Tominaga et al. 2003). Due to the abundance of this myosin class, representing most of the myosins in higher plants (Reddy and Day 2001), even a minor effect of BDM on class XI might be meaningful.

From the highly divergent tail domains within each myosin class, one can expect differential functions for the individual family members. Our observation that cell division, but not cell elongation, is affected by BDM might indicate that different myosins with different sensitivity to the inhibitor are involved. This cannot be resolved at this stage, however, but would require either in vitro studies with specified individual myosins and/or the use of cell lines in which given myosins are either overexpressed or knocked out.

\section{Structural and motile functions of plant myosins}

That BDM interferes with the proper distribution of vesicles in VBI-0 cells is shown in Fig. 1. Here, the accumulation of vesicles around the nucleus as well as along the cross walls was the earliest change after treatment with $\mathrm{BDM}$ at higher concentrations $(30-50 \mathrm{mM})$ in short-term experiments $(2-3 \mathrm{~h})$. These vesicle clusters indicate an impaired translocation of vesicles from the cell center to the periphery, consistent with numerous studies that show a block of Golgi and endoplasmic-reticulum traffic as well as of cytoplasmic streaming (Molchan et al. 2002, Nagai 1979, Nebenführ et al. 1999, Tominaga et al. 2000, Yokota et al. 2000). These altered motile properties can be either a direct consequence of altered myosin motor activity due to the stabilized ADP. $P_{i}$ status caused by BDM (Geeves and Holmes 1999). Alternatively, BDM could affect myosins more indirectly via signal molecules. For example, BDM has been shown to alter the activity of myosin II light-chain kinase in skeletal muscle (Siegman et al. 1994). Plant myosins, which can be regulated through calcium/calmodulin (Yokota et al. 1999), calcium-regulated kinases and phosphatases, have been discussed as targets for the effect of BDM on actin tension and organization (Grabski et al. 1998).

In addition to the motile function of myosins for vesicle transport, they seem to be essential for the spatial organization of actin microfilaments as seen from the progressive disorganization of the actin cytoskeleton (Fig. 6). Similar to most vacuolated cells of higher plants, VBI-0 shows an alignment of subcortical actin bundles with the cell axis (Parthasarathy et al. 1985). Myosins could be involved in this alignment by interconnecting actin microfilaments among themselves as well as with membranes. When this function is blocked by lowering the affinity between actin and myosin (as in the case of BDM), the alignment of the actin microfilaments with the cell axis would progressively vanish. In fact, the axially aligned microfilament bundles of the subcortex disappeared in parallel with the axially aligned cytoplasmic strands. The localization of a class VIII myosin at plasmodesmata and pit fields indicates a role of myosins for the anchoring of microfilaments at cross walls (Reichelt et al. 1999). If this anchoring process is BDM sensitive, the alignment of actin microfilaments is expected to disappear after BDM treatment, which has been observed in the present study. These findings suggest that, in addition to their motor function, myosins fulfill a kind of "structural function" for the organization of actin arrays.

However, in VBI-0 the reponse of actin microfilaments to BDM can vary. This is shown by the cortical, transverse microfilaments which are more persistent to BDM than the axially aligned microfilaments (Fig. 6B). The different response of different actin subpopulations to BDM argues against nonspecific or general effects of BDM. It might moreover indicate that their organization depends on a different mechanism and that other actin-modulating or -cross-linking proteins could be involved which are not influenced by BDM.

The disorganization of actin alignment through an inhibition of myosin function might also be the cause for the 
malformations observed in the tip-growing terminal cells. The localization of the growth center is correlated with the dynamic organization and polarity of actin in tipgrowing cells (Vidali and Hepler 2001). When the alignment of these bundles is disturbed, the growth center will shift erroneously to a new location, producing lateral bulges that become manifest as pear-shaped malformations (Fig. 4).

\section{Inhibition of cell plate formation versus inhibition of auxin signaling}

By immunofluorescence, myosins were visualized in callosic cell plates and young cross walls (Chaffey and Barlow 2002, Reichelt et al. 1999), where they may have important functions for the maturation of cell plates and the adjustment of plasmodesmata (Reichelt et al. 1999). In Tradescantia virginiana stamen hair cells, treatment with $\mathrm{BDM}$ was reported to produce disoriented, oblique cross walls, which is accompanied by a block of cytoplasmic streaming (Molchan et al. 2002). In the present study, the cross walls are observed to broaden in a diffuse manner accompanied by fine lamellate structures and an accumulation of vesicular structures around the nucleus (Fig. 5). These findings support a scenario in which BDM would impair cell division by blocking the transport of vesicles delivering components required for cell division. If one would only assume changes in the transport of cellwall-specific components, one would expect comparable inhibitory effects for cell elongation as for cell division because of a general decline of cell wall formation. Since cell expansion still proceeded (Figs. 1-3), the impaired cell division cannot be just the consequence of a reduced mass flow of vesicles. One can therefore assume that BDM affects pathways which are much more related to cell division than to cell elongation. This is supported by a different line of evidence. Since mitosis and cytokinesis can be uncoupled, impaired cell plate formation would result in polyenergid cells - which was actually observed when VBI-0 cells were treated with caffeine, a blocker of cell plate formation (Holweg, unpubl. results). But polyenergid cells were not observed in the present study. Thus, the high sensitivity of cell division to BDM cannot be explained in terms of impaired cell plate formation, but must be related to events that precede mitosis.

The onset of the first division leading to the bicellular state was delayed by about 2 days in the presence of BDM (Fig. 1D). In the tobacco cell line BY-2, a similar delay of cell division can be produced by auxin starvation (Chen 2001), indicating that BDM interferes with the proper per- ception or processing of the auxin signal triggering cell division. One might conceive a situation in which components of auxin signalling are transported by actomyosin to their site of action. In order to ensure a high flexibility and the ability for response habituation, these components would be recycled continuously, such that the block of vesicular transport by BDM would result in a reduced sensitivity to auxin and delayed auxin responses. In fact, a block of vesicle flow by low concentrations of the inhibitor Brefeldin A desensitized the auxin response of maize coleoptiles (Waller et al. 2002) and inhibitors of microfilament assembly interfere with the intracellular movement of a putative auxin efflux carrier, PIN1 (Geldner et al. 2001). Support for this proposal of a vesicle-driven auxin transport is given in a recent report summarizing data about polar auxin transport to a finally favored "neurotransmitter-like" concept of "vesicle-trafficking-based secretion of auxin" (Baluška et al. 2003).

When BDM blocks cell division through impairing auxin control of this process, why does it then not inhibit cell expansion? Division and expansion, although both under the control of auxin, can be clearly separated in the tobacco cell culture BY-2, consistent with a model in which two independent auxin receptors trigger independent (but antagonistically cross talking) signalling chains (Chen 2001). If the signal triggering the cell cycle would be blocked, cell expansion would be stimulated by this antagonistic cross talk. The antagonism between cell expansion and cell division is a peculiar characteristic of auxin signalling that is observed, for instance, during the overexpression of auxin-binding proteins (Jones et al. 1998).

\section{Outlook}

The present study has identified cellular events that are controlled by myosins. These include the maintenance of polarity in the terminal cells as well as the alignment of subcortical actin bundles with the cell axis and the transport of vesicles. Cell division was found to be the most sensitive target for the action of BDM, whereas cell expansion seemed to be much more independent and in suspension cells even continued in the presence of this inhibitor. The inhibition of cell division by BDM cannot be explained by potential effects of BDM on cell plate formation but must reside in the regulatory network that triggers the cell cycle in response to auxin. An attractive possibility might be the actomyosin-based transport of auxin-signaling components that are turned over rapidly.

The findings of this study can now be used as physiological framework to investigate the potential function of 
individual myosins. This will require the use of specific probes. For this purpose, we generated a collection of fusion constructs that are linked to different myosin classes and can be used in transient-transformation experiments to investigate their localization and cellular function. In addition, class-specific antibodies are generated that can be used to assess changes of localization during auxintriggered cell division.

\section{Acknowledgment}

The present study was financed by the Volkswagen-Stiftung (Nachwuchsgruppe Dynamik des pflanzlichen Zellskeletts).

\section{References}

Baluška F, Jasík J, Edelmann HG, Salajová T, Volkmann D (2001) Latrunculin B-induced plant dwarfism: plant cell elongation is F-actin dependent. Dev Biol 231: 113-124

- Šamaj J, Menzel D (2003) Polar transport of auxin: carrier-mediated flux across the plasma membrane or neurotransmitter-like secretion? Trends Cell Biol 13: 282-285

Baskin TI, Bivens NJ (1995) Stimulation of radial expansion in Arabidopsis roots by inhibitors of actomyosin and vesicle secretion but not by various inhibitors of metabolism. Planta 197: 514-521

Chaffey N, Barlow P (2002) Myosin, microtubules, and microfilaments: co-operation between cytoskeletal components during cambial cell division and secondary vascular differentiation in trees. Planta 214: 526-536

Chen JG (2001) Dual auxin signaling pathways control cell elongation and division. J Plant Growth Regul 20: 255-264

Geeves MA, Holmes KC (1999) Structural mechanism of muscle contraction. Annu Rev Biochem 68: 687-728

Geitmann A, Emons AMC (2000) The cytoskeleton in plant and fungal cell tip growth. J Microsc 198: 218-245

Geldner N, Friml J, Stierhof YD, Jürgens G, Palme K (2001) Auxin transport inhibitors block PIN1 cycling and vesicle trafficking. Nature 413: 425-428

Grabski S, Arnoys E, Busch B, Schindler M (1998) Regulation of actin tension in plant cells by kinases and phosphatases. Plant Physiol 116: 279-290

Heller R (1953) Studies on the mineral nutrition of in vitro plant tissue cultures. Ann Sci Nat Bot Biol Veg 14: 1-223 (in French)

Herrmann C, Wray J, Travers F, Barman T (1992) Effect of 2,3-butanedione monoxime on myosin and myofibrillar ATPases: an example of an uncompetitive inhibitor. Biochemistry 31: 12227-12232

Higuchi H, Takemori S (1989) Butanedione monoxime suppresses contraction and ATPase activity of rabbit skeletal muscle. J Biochem 105: 638-643

Johannes E, Brosnan JM, Sanders D (1991) Calcium channels and signal transduction in plant cells. BioEssays 13: 331-336

Jones AM, Im KH, Savka MA, Wu MJ, DeWitt G, Shillito R, Binns AN (1998) Auxin-dependent cell expansion mediated by overexpressed auxin-binding protein 1 . Science 282: 1114-1117

Karlsson R, Lindberg U (1985) Changes in the organization of actin and myosin in non-muscle cells induced by N-ethylmaleimide. Exp Cell Res 157: 95-115

Katsuta J, Shibaoka H (1988) The roles of the cytoskeleton and the cell wall in nuclear positioning in tobacco BY-2 cells. Plant Cell Physiol 29: $403-413$
Lloyd CW (1991) Cytoskeletal elements of the phragmosome establish the division plane in vacuolated plant cells. In: Lloyd CW (ed) The cytoskeletal basis of plant growth and form. Academic Press, London, pp 245-257

McCurdy DW (1999) Is 2,3-butanedione monoxime an effective inhibitor of myosin-based activities in plant cells? Protoplasma 209: 120-125

McKillop DF, Fortune NS, Ranatunga KW, Geeves MA (1994) The influence of 2,3-butanedione monoxime (BDM) on the interaction between actin and myosin in solution and in skinned muscle fibres. J Muscle Res Cell Motil 15: 309-318

Menzel D, Elsner-Menzel C (1989) Actin-based chloroplast rearrangements in the cortex of the giant coenocytic green alga Caulerpa. Protoplasma 150: 1-8

Molchan TM, Valster A, Hepler PK (2002) Actomyosin promotes cell plate alignment and late lateral expansion in Tradescantia stamen hair cells. Planta 214: 683-693

Mooseker MS, Cheney RE (1995) Unconventional myosins. Annu Rev Cell Dev Biol 11: 633-675

Murata T, Wada M (1991) Effects of centrifugation on preprophase-band formation in Adiantum protonemata. Planta 183: 391-398

Nagai R (1979) Cytoplasmic streaming in plant cells. Plant Physiol 10: $45-48$

Nebenführ A, Gallagher LA, Dunahay TG, Frohlick JA, Mazurkiewicz AM, Meehl JB, Staehelin LA (1999) Stop-and-go movements of plant Golgi stacks are mediated by the acto-myosin system. Plant Physiol 121: $1127-1141$

Nick P (1998) Signaling to the microtubular cytoskeleton in plants. Int Rev Cytol 184: 33-80

Opatrný Z, Opatrná A (1976) The specificity of the effect of 2,4-D and NAA on the growth, micromorphology and the occurrence of starch in long-term Nicotiana tabacum cell strains. Biol Plant 18: 381-400

Ostap E (2003) 2,3-Butanedione monoxime (BDM) as a myosin inhibitor. J Muscle Res Cell Motil 23: 305-308

Parthasarathy MV, Perdue TD, Witztum A, Alvernaz J (1985) Actin network as normal component in many vascular plant cells. Am J Bot 72 : $1318-1323$

Petrašek J, Freudenreich A, Heuing A, Opatrný Z, Nick P (1998) HSP90 is associated with microtubules in tobacco cells. Protoplasma 202: 161-174

Radford JE, White RG (1998) Localization of a myosin-like protein to plasmodesmata. Plant J 14: 743-750

Reddy A, Day I (2001) Analysis of the myosins encoded in the recently completed Arabidopsis thaliana genome sequence. Genome Biol 2(7): research 0024.1-0024.17

Reichelt S, Knight AE, Hodge TP, Baluska F, Samaj J, Volkmann D, Kendrick-Jones J (1999) Characterization of the unconventional myosin VIII in plant cells and its localization at the post-cytokinetic cell wall. Plant J 19: 555-567

Saitoh M, Ishikawa T, Matsushima S, Naka M, Hidaka H (1987) Selective inhibition of catalytic activity of smooth muscle myosin light chain kinase. J Biol Chem 262: 7796-7801

Šamaj J, Peters M, Volkmann D, Baluška F (2000) Effects of myosin ATPase inhibitior 2,3-butanedione 2-monoxime on distributions of myosins, F-actin, microtubules, and cortical endoplasmic reticulum in maize root apices. Plant Cell Physiol 41: 571-582

Sellers JR (2000) Myosins: a diverse superfamily. Biochim Biophys Acta 1496: 3-22

Sellin LC, McArdle JJ (1994) Multiple effects of 2,3-butanedione monoxime. Pharmacol Toxicol 74: 305-313

Shimmen T, Ridge RW, Lambiris I, Planzinski J, Yokota E, Williamson RE (2000) Plant myosins. Protoplasma 214: 1-10

Siegman MJ, Mooers SU, Warren TB, Warshaw DM, Ikebe M, Butler TM (1994) Comparison of the effects of 2,3-butanedione monoxime on force production, myosin light chain phosphorylation and chemical 
energy usage in intact and permeabilized smooth and skeletal muscles. J Muscle Res Cell Motil 15: 457-472

Sonobe S, Shibaoka H (1989) Cortical fine actin filaments in higher plant cells visualized by rhodamine-phalloidin after pretreatment with $\mathrm{m}$ maleimidobenzoyl N-hydroxysuccinimide ester. Protoplasma 148: $80-86$

Staiger C (2000) Signaling to the actin cytoskeleton in plants. Annu Rev Plant Physiol Plant Mol Biol 51: 257-288

Thimann KV, Reese K, Nachmikas VT (1992) Actin and the elongation of plant cells. Protoplasma 171: 151-166

Tominaga M, Yokota E, Sonobe S, Shimmen T (2000) Mechanism of inhibition of cytoplasmic streaming by a myosin inhibitor, 2,3-butanedione monoxime. Protoplasma 213: 46-54

- Kojima H, Yokota E, Orii H, Nakamori R, Katayama E, Anson M, Shimmen T, Oiwa K (2003) Higher plant myosin XI moves processively on actin with $35 \mathrm{~nm}$ steps at high velocity. EMBO J 22: 1263-1272
Vidali L, Hepler PK (2001) Actin and pollen tube growth. Protoplasma 215: 64-76

Waller F, Nick P (1997) Response of actin microfilaments during phytochrome-controlled growth of maize seedlings. Protoplasma 200: 154-162

Waller F, Riemann M, Nick P (2002) A role for actin-driven secretion in auxin-induced growth. Protoplasma 219: 72-81

Yamashita RA, Sellers JR, Anderson JB (2000) Identification and analysis of the myosin superfamily in Drosophila: a database approach. J Muscle Res Cell Motil 21: 491-505

Yokota E, Muto S, Shimmen T (1999) Inhibitory regulation of higherplant myosin by $\mathrm{Ca}^{2+}$ ions. Plant Physiol 119: 231-239

- Imamichi N, Tominaga M, Shimmen T (2000) Actin cytoskeleton is responsible for the change of cytoplasmic organization in root hair cells induced by a protein phosphatase inhibitor, calyculin A. Protoplasma 213: 184-193 